\title{
TUMORES DE OVARIO GIGANTES ASOCIADOS CON EMBARAZO
}

\author{
Instïtuto Materno Infantil - Servicio de Ginecología, Bogotá \\ Dr. Marco A. Hernández Romero* \\ Dr. Leonardo Arzuza Estrada **
}

\section{Introducción:}

Los tumores de ovario, según Norris H. J. y Cols (7), se asocian frecuentemente con embarazo y constituyen un serio problema cuando alcanzan grandes tamaños, pues complican el embarazo ya sea por torsión de su pedículo, o al actuar como tumor previo lo cual obliga a realizar una operación cesárea tal como anota en su trabajo Persuad V. y Cols (11).

Según Kaeser y Cols (5) los quistes pequeños del ovario, del tamaño de 6-8 cm, pueden confundirse con un embarazo extrauterino, o puede ser un embarazo intrauterino precoz y palparse la masa que corresponde a un cuerpo amarillo del embarazo y como tal se debe dejar en observación. Excepcionalmente los quistes ováricos del embarazo son malignos (5).

En el $75 \%$ de las mujeres con este tipo de tumor y embarazo en el Columbian Presbitarian Medical Center el hallazgo fue efectuado a finales del embarazo.
El objetivo del presente trabajo es presentar una revisión de 3 casos de tumores gigantes de ovario poco frecuentes, asociados al embarazo.

\section{Material y métodos:}

Se presentan 3 casos de tumores de ovario poco frecuentes asociados con embarazo, hospitalizados y tratados en el servicio de Ginecología del Instituto Materno Infantil de Bogotá "Concepción Villaveces de Acosta". Según el informe de Patología son los 3 primeros casos de su género asociados con embarazo que se informan en el Instituto y como coincidencia, los 3 casos se presentaron durante el año de 1976.

Dicha revisión se hizo en los últimos diez años, encontrándose

Residente 2 del Departamento de Obstetricia y Ginecología. Facultad de Medicina (Universidad Nacional).

*: Residente 3 del Departamento de Obstetricia y Ginecología. Facultad de Medicina (Universidad Nacional). 
tres pacientes con embarazo y tumor las cuales se intervinieron en diferentes circunstancias obteniéndose un tecoma, un quiste folicular y un quiste del cuerpo luteo, gigante.

\section{Primer caso:}

Paciente de 19 años G1 P1 A0 C1, que fue vista por primera vez a las 38 semanas de embarazo por presentar contracciones uterinas dolorosas. Sus períodos menstruales comenzaron a los 14 años y habían sido ncrmales. Al examen el tamaño del útero correspondía al período de amenorrea. Se palpaba una masa de $20 \times 15 \mathrm{~cm}$, no adherida, relativamente móvil, no dolorosa. Los genitales externos y el cervix eran normales. Se hizo un diagnóstico clínico de trabajo de parto y tumor ovárico previo. Se practicó una laparatomia extrayéndose sin dificultad un tumor sólido de $17 \times 15 \mathrm{cms}$, de cápsula lisa, sin adherercias, practicándo. se lueqo una cesárea segmentaria obteniéndose un recién nacido normal. Los otros órganos fueron normales. Se hizo salpingo-oforectomía izquierda y biopsia de ovario derecho. Evolucionó mal en el post-operatorio inmediato por dehiscencia de histerorrafia y peritonitis por lo cual se intervino nuevamente practicándosele histerectomía.

El último control 6 meses más tarde es satisfactorio.

\section{Hallazgos histopatológicos:}

Se trataba de un tumor de partes quísticas y sólidas que medía $15 \times 15 \mathrm{~cm}$, sin adherencias, de cápsula lisa, y que fue clasificado histológicamente como un Tecoma.

\section{Comentario}

Al hablar de los tecomas es clásico señalar a Persuad V. y a Diddle A. W. (11) como los primeros en describirlos en 1932 como una entidad con el nombre de "Fibroma Tecacelular Zantomatoide".

El tumor de la teca posee actividad endocrina y produce hormo na folicular (13). En casos muy raros se han descrito tumores de células de la teca atípicos con acción lejana androgénica; la neoformación es benigna, según Novak, Jones-Jones (9). Las formas malignas, que representan el $2.6 \%$ aproximadamente de los casos, aparecen por lo general después de los 50 años de edad (15).

El tecoma se clasifica como un tumor del estroma gonadal; se traza la génesis de los tecomas a partir de la hiperplasia estromocortical (8).

Estos tumores varían de tamaño, desde unos pocos milímetros de diámetro hasta formaciones de tamaño considerable (8). Microscópicamente se encuentran paquetes de células fusiformes anchas, de aspecto epiteloide distribuidos en forma entrelazada separados por bandas de tejido conectivo. Existe gran cantidad de grasa birrefringente dentro de las células y en el tejido circundante. Esto es muy sugestiva pero no patognomónico de actividad esteroide (13). Clínica. mente los tecomas se comportan como cualquier tumor de ovario; por eso no entramos en su consideración.

Se cita la asociación con embarazo en la Literatura mundial según Gillibrand en 27 pacientes y afirma 
que su existencia es rara ya que habitualmente estos pacientes son €stériles. Cuando un tecoma ováririco se presenta después de la mitad del embarazo es en particular peligroso. El tumor tiende a crecer rápidamente y puede complicarse por la torsión, con la ruptura o con obstrucción del trabajo (7-15). Tres de los casos, informados por Beltrán Suárez (1) murieron en el postparto inmediato por hemorragia intraperitoneal debido a ruptura del tumor. El tumor de las células tecales del ovario es causa frecuente de esterilidad o de aborto (11. 18).

La esterilidad se produce por la inhibición de la ovulación causado por los altos niveles de estrógenos secretados por el tumor(17).

Se han reportado dos casos de virilismo en embarazo asociados con tecoma ovárico en el trabajo die Diddle, A. W. and C' connor $\mathrm{K}$. A. Patton C. L. and Patton R. J. (210); aunque en uno de los pacientes la remosión del tumor se acompañó de desaparición de la masculinización, la regresión fue parcial en el otro caso.

El mecanismo exacto es difícil de explicar pero hay evidencia de que las células tecales secretan andrógenos (3).

El tecoma ovárico asociado con embarazo debe ser diferenciado microscópicamente del luteoma del embarazo. Este ocurre más a me nudo en pacientes con alta paridad y es generalmente descubierto cerca al término (4). Es una lesión que ocurre en el ovario solamente en el embarazo y aeneralmente regresa después de él (6).

\section{Segurdo caso:}

Paciente de 20 años G2 P2 A0. Fue vista por primera vez a las 40 semanas del embarazo por presentar contracciones uterinas dolorosas unas horas antes de su ingreso. Se le atendió parto espontáneo con feto vivo normal. Consultó por segunda vez a los 17 días por masa y dolor abdominal. Sus períodos menstruales comenzaron a los 17 años y habían sido normales. Al examen el tamaño del útero correspondía al tiempo del puerperio. Se encontró una masa palpable que llenaba el abdomen, de $30 \times 30 \mathrm{~cm}$. renitente, relativamente móvil, y no dolorosa a la palpación. Los genitales externos y el cérvix eran normales.

Se hizo diaanóstico clínico de tumor ovárico. Se practicó una laparatomía extrayéndose sin mucha dificultad un tumor quístico de 20 x $20 \mathrm{cms}$. de diámetro. Los otros órganos pélvicos se observaron normales. Se le practicó resección del quiste de ovario derecho y biop. sia del ovario izquierdo.

Evolucionó satisfactoriamente. El último control a los 11 meses era normal.

\section{Hallazgcs histopatológicos:}

Se trataba de un tumor quístico de $20 \times 20 \mathrm{~cm}$. de diámetro, de consistencia blarida, al corte contenía abundante material sero-sanguino* lento y presentaba alqunas membranas de aspecto fibrinoso. El diagnóstico definitivo fue de "Cuerpo amarillo quístico". La cuña del cvario contralateral fue normal. Es un caso interesante por tratarse de un quiste muy grande del cuerpo 
lúteo, el más grande que se ha visto en el Instituto, según concepto del Patólogo.

\section{Comentario:}

El origen del verdadero quiste luteínico es en la mayor parte de los casos un hematoma del cuerpo lúteo(14).

Este último, a su vez, es producido por aumento de la hemorragia que normalmente tiene lugar en el interior de la cavidad del cuerpo durante la fase llamada de vascularización.

uuando la hemorragia es excesiva, se produce un voluminoso hematoma del cuerpo lúteo caracterizado principalmente por una pared luteínica, adelgazada, de color amarillo brillante, que rodea la cavidad central repleta de sangre (14). Progresivamente, no obstante, se reabsorben los elementos sanguíneos, dejando un líquido claro o ligeramente sanguinolento (16). Los síntomas de estos quistes, se asemejan a los del embarazo tubárico (9).

La menstruación suele estar ligeramente retardada y a continuación de ella se presenta una hemorragia ligera y persistente (8). El diagnós. tico de los quistes del cuerpo lúteo es evidentemente difícil y en la mayoría de los casos no se sospecha su presencia antes de la operación (12). El tratamiento de los quistes del cuerpo lúteo consiste en vigilarlos pues casi todos desaparecen espontáneamente (7). Tra. tándose de quistes hemorrágicos de tamaño considerable, o cuando hay señales de hemorragia intraperitoneal, la extirpación constituye el tratamiento apropiado por el peligro de hemoperitoneo masivo (11).

\section{Tercer caso:}

Paciente de 19 años G1 P1 A0, quien fue vista por primera vez a las 14 semanas de embarazo por presentar dolor abdominal de 11 días de evolución. Sus períodos menstruales comenzaron a los trece años y habían sido normales. Al examen el tamaño del útero correspondía al período de amenorrea. Se encuentra una masa palpable de 22 x $17 \mathrm{~cm}$., central, regular, dura, móvil. no dolorosa. Los genitales externos y el cérvix eran normales.

Se hizo diagnóstico clínico de tumor ovárico. Se practicó una lapa. ratomía extrayéndose un tumor quístico de $20 \times 18 \mathrm{~cm}$. sin mucha dificultad. Los otros órganos pélvicos fueron normales. Se le practicó salpingooforectomía izquierda. Evclucionó satisfactoriamente. Ultimo control a los dos meses apreciándose que el embarazo seguía su curso normal.

\section{Hallazgos histopatológicos:}

Se trataba de un quiste que midió $18 \times 10 \mathrm{~cm}$., con una cápsula de $0.2 \mathrm{~mm}$. La superficie externa era lisa, brillante, con algunas adherencias. Se hizo un diagnóstico de "quiste de retención folicular".

\section{Comentario:}

El quiste de retención folicular nace de la hiperdistensión de los folículos durante el proceso de atresia folicular (8). Muchas veces la cavidad se halla extraordinariamente distendida por líquido, produciendo quistes importantes por 
su volumen (11-17). Se puede producir hemorragia en el interior de la cavidad del quiste dando lugar al Ilamado hematoma folicular (9). Los síntomas son como los de cualquier tumor ovárico. El diagnóstico solo puede hacerse por la Cirugía. Los quistes pequeños pueden reabsorberse espontáneamente. Los quistes de tamaño considerable o complicados ameritan su extirpación (5).

\section{Resumen:}

Se hace la revisión de 3 casos interesantes de tumores ováricos asociados con embarazo, estudiados y tratados en el Instituto Materno Infantil de Bogotá. Dos de ellos fueron descubiertos durante el embarazo; uno con gestación a término y el otro a las 14 sema. nas. El tercer caso se descubrió a los 20 días de puerperio. Fueron descritos como tecoma, quiste folicular y quiste del cuerpo lúteo respectivamiente; todos gigantes, siendo los primeros que se diagnostican en el Instituto asociados a embarazo.

Se indica además el tratamiento quirúrgico que se practicó en cada caso. Todos los controles posteriores fueron satisfactorios.

\section{Summary:}

A revision is made of three interesting cases of ovarian tumors associated with pregnancy, which have been studied and treated at the Instituto Materno-Infantil (Mother and Child Institute) in Bogotá.

Of these tumors, two were discovered during pregnancy, one in a terminal gestation and the other at fourteen weeks of pregnancy. The third one was discovered 20 days after puerperium. Described as thecoma, follicular cyst and cyst of the corpus luteum respectively, all of them were gigantic and are the first tumors associated with pregnancy which are discovered at the Institute.

The surgery treatment for each case is also explained. All subsequent controls were satisfactory.

\section{BIBLIOGRAFIA}

1. Beltrán Suárez R. Correa P. y Gómez. "Tumores feminizantes de Ovario". Ginecol. Obstec. Mex. 32: 43, 1974.

2. Diddle A. W. and O'Connor, K. A. "Feminizant Ovarian Tumors and Pregnancy" Am J. Obstet Gynec 62: 1971.

3. Dougherty C. M. and Lund, C. J. "Solid Ovarian Tumors Complicating Pregnancy: Clinical Pathological Study". Am J. Obstet Gynec 60: 261, 1973.

4. Gillibrand P. N. "Feminizang Ovarian Tumors". and J. Obstet Gynec 94: 1108. 1972.

5. Kaser, O. y Cols.: Ginecología Especial Volumen III, Pág. 535: 541. Salvat Editores, 2" Edición 1974.

6. Norin, P., Busbyt et Anderson G. W. "Ovarian Follicule The coma". Bull Fed Gynecol Obstst Fane 21: 32, 1974 .

7. Norris H. J. Doughrty, C. M. and Lund, G. J. "Functioning tumors 
of the ovary. "Clin Obstec-Ginecol. 17: 189, 1974 .

8. Novack and Woodrufi. "Gynecologic and Obstetric Pathology". 357: 366. W. B. Saunders Company. Seventh. Edition 1974.

9. Novack Jones Jones "Tratado de Ginecología”. pág. 512: 541. Editorial Interamericana $8^{*}$ Edición 1970.

10. Patton, Cl. and Patton L, J. "Ovarian Thecoma" case report with cintrasting symptomatology. Illinois M. J. 94: 184. 1971.

11. Persuad, V. Diddle, A. W. and $\mathrm{O}^{\prime}$ Connor, K. A. "Thecacel tumor of the ovary associated with pregnancy. "Int. Surg. 53: 48, 1970.

12. Pschyrembel WW. "Ginecología Práctica, Volumen I, 389: Editorial Alhambra, S. A. España, 4" Edición. 1973.
Rev. Col. Obst. y Ginec.

13. Robbins L. Stanley. "Tratado de Patología. Volumen I. pág. 1050. Editorial In'eramericana $8^{n}$ Edición, 1970.

14. Shippel, S. Ovarian "Theca cell: Hiperethecosis Syndromen. J. Obstet Gynec. Brit Emp. 62: 321, 1975.

15. Stenberg W. H. snf Barclay, D. L. "Feminizang Ovarian Tumors and Pregnancy". D. L. Obstet Gynec 95: 165, 1973.

16. Stout, A. P. "Thecal cell tumor of Ovary with Masculinizatior in Pregnani, Woman" Texas J. 41: $551,1972$.

17. Talerman A., and James E. M. "Ovarian Tumors". Obstet Gynec 31: 45, 1974.

18. Webb C. F. and Gough J. A. "Tehca cell tumors of Ovary associated with Term Pregnancy "Am J. Obstet Gynec 65: 211, 1973. 